\title{
COVID-19 and changes to postgraduate medical education in Canada
}

\author{
Colm McCarthy MDCM MSc HSc Ed, Kallirroi Carayannopoulos MD, J. Mark Walton MD
}

Cite as: CMAJ 2020 August 31;192:E1018-20. doi: 10.1503/cmaj.200882

$\mathbf{T}$ he coronavirus disease 2019 (COVID-19) pandemic has fundamentally changed society and the delivery of health care in Canada. Given that much health care is delivered by residents, postgraduate medical education has also had to transform. Residents have been redeployed and rotations modified, moved or suspended. Procedural specialties postponed many elective surgeries and many clinics have transitioned to a virtual model. In an unprecedented decision, certifying colleges cancelled oral examinations and postponed written ones to the fall of 2020., ${ }^{1,2}$ Amid efforts to prevent a surge in infections caused by severe acute respiratory syndrome coronavirus 2 (SARS-CoV-2) that could overwhelm the health care system, Canada has entered a new paradigm of medical education. ${ }^{3}$ How can we minimize infection risk for patients, learners and supervisors, yet continue to deliver optimal training for postgraduate medical learners in Canada?

Recruitment of residents for both postgraduate year 1 (PGY-1) and subspecialty positions has traditionally relied on crosscountry travel for in-person interviews, followed by use of a matching algorithm. In 2021, however, residency interviews will be conducted online, saving both candidates and programs substantial costs. Although eliminating or reducing travel costs could potentially make selection more equitable, well-connected candidates may still be at an advantage, and program selection committees may find it difficult to make decisions without face-toface meetings. Peer references, such as resident letters, could be used to promote an honest and equitable approach to the selection process. Travel has historically allowed for cross-pollination of education between provinces and institutions, which is of particular importance in areas where certain specialties are not available. Eliminating travel for electives or interviews may lead to fewer opportunities for doctors in more rural training programs to bring subspecialty knowledge back to their local communities.

Onboarding and orientation of new residents and subspecialty fellows will be challenging. Those moving from locations with high prevalence of COVID-19 (both within Canada and internationally) may be required to temporarily self-isolate. Provision of identification badges must shift to either an online process using photo applications or acquisition systems that prevent large gatherings. Resident "boot camps" will require larger spaces and new resources to conform to physical-distancing

\section{KEY POINTS}

- The way in which residents are recruited, learn and practise in Canada has changed fundamentally with the coronavirus disease 2019 (COVID-19) pandemic; the crisis has created a need and opportunity to overcome institutional and historic barriers to change, facilitating rapid implementation of educational advancements.

- Technology and novel means of learning, including online resources, simulation, video conferencing and virtual reality, must be embraced to facilitate ongoing medical education.

- Clear documentation of completed and remaining competencies can and must continue to be done.

- Faculty development will be integral to medical education - in particular, the identification of early successes and adoption of creative methods of delivery.

- National written examinations must be transitioned to a reliable online format. In-person practical examinations must be critically appraised, with consideration for the safety of participants and assessors.

guidelines, or orientation may need to be delivered virtually. Ensuring competency in donning and doffing personal protective equipment (PPE) will be an immediate priority for new starters.

Support systems for postgraduate medical learners will need to expand their scope to acknowledge the additional stress related to COVID-19 in the context of already challenging training. Wellness office resources, therapists and counselling must be accessible online.

Programs are entrusted with the safety of their medical learners and learners are, in turn, entrusted with the safety of the patients they encounter and treat. It will be crucial to maintain the safety of both patients and medical learners in the era of COVID19 , with additional complexity added to the traditionally graded responsibility entrusted to residents. Although graduated responsibility remains paramount, the focus will be shifted by the risks of COVID-19. Precautions against airborne and droplet spread of SARS-CoV-2 are critical early competencies. All residents will need to develop the capacity to independently manage patients at high risk, including knowing how to protect themselves and others during aerosol-generating medical procedures. 
Several strategies have already been employed to mitigate risk to physician learners, while optimizing continued clinical care. In some locations, residents have been required to work within a single hospital or travel less when on call within a city. Some residents have been redeployed and exposure to elective procedures and surgeries may have been minimized. Residents who are immunocompromised or pregnant have been preferentially reassigned away from the care of patients who are infected or at high risk of infection. ${ }^{4}$ In some settings, staff have been divided into groups, with some working in the care environment as others focus on research or education via online resources. ${ }^{5}$ Although these changes are designed to optimize safety, residents may have less diversity in supervision and fewer learning opportunities than in the past. The impact of these changes may be most important for senior residents who still require key clinical exposures to establish competencies and confidence.

Some have questioned how the attainment of core competencies and skills will be affected by the pandemic. The development of The College of Family Physicians of Canada's competencybased curriculum ${ }^{6}$ and the Royal College of Physicians and Surgeons of Canada's CanMEDS 2015 physician competency framework $^{7}$ shifted the focus of postgraduate medical education toward acquisition of the qualities of a competent physician. Moreover, both colleges have been transitioning to a competencybased assessment and training model. The ongoing launch of the Royal College's Competency by Design model is in jeopardy. Adoption of this model was already a source of stress for clinicianeducators, who are now further burdened with the stress of COVID-19. Fewer than half of Canada's residency programs had begun implementation of the Competency by Design model, and 8 of 17 specialties and subspecialties have deferred their start from 2020 until 2021. ${ }^{8}$ However, competency-based medical education may be even more important in a COVID-19 world.

It is vital that, given reduced clinical learning opportunities, residents remain cognizant of their skill gaps so that these can be identified and corrected through future self-directed learning. In addition, a pillar of competency-based medical education is tracking and identifying these gaps, which could lead to more equitable training among the entire program. Learners may employ case logs and track milestones as suggested within the competency-based medical education model. ${ }^{9}$

One of the hallmarks of the transition from junior to senior medical resident is leading codes; this is usually achieved by inperson coaching of junior residents by their seniors. However, COVID-19 is likely to change this learning tradition because the number of providers at a patient's bedside will need to be at a minimum to optimize everyone's safety. In the future, teaching of emergency interventions may require physicians to embrace technologies like Bluetooth headphones or baby monitors, with competency assessments based on body camera video recordings, for example. Similarly, surgical specialties may need to employ virtual and augmented reality technologies to teach surgical techniques and allow feedback while minimizing infectious risks. ${ }^{10}$

The days of crowded bedside rounds are over; infection control protocols for physical distancing must be followed and the consumption of valuable PPE reduced. Training place assessments and patient care will remain the essence of medical education; however, creativity and innovation will be required to deliver these foundations. ${ }^{11}$ Medical learning through virtual care provides a challenge to patients, staff and learners alike. Ensuring patient privacy is of crucial importance. Institutional and personal barriers to adoption of new technological resources ${ }^{12}$ will need to be overcome to ensure that learning objectives are met and competencies properly developed. ${ }^{13}$ Synchronous and asynchronous resources are being generated using videos and webinars. Video conferencebased grand rounds and academic half days have become normal. Video-based learning can be challenging but also presents an opportunity for innovation in the delivery and organization of medical teaching, because geographically distant institutions or sites can engage in academic activities nationwide and international speakers can easily participate. Canadian medicine has the opportunity to become more unified nationally. Medical conferences are being reimagined, ${ }^{14}$ which may allow for an increase in the scope of knowledge dissemination alongside the benefits of reduced cost and environmental impact of conferences.

Faculty development was an important component of delivering competency-based medical education before COVID-19 and must remain so. The development and implementation of new teaching strategies, such as new modalities of delivering information, will require teachers to learn new techniques and develop new skills. Simulation and virtual and remote assessment are just a few modalities being explored at present. Residents, who are often familiar with new technologies, may be helpful in teaching their supervisors to navigate online resources and telemedicine.

Postgraduate medical education is heavily based on a fee for service model for its delivery. With the cancellation or loss of scheduled procedures and clinics, preceptors potentially face reduced pay even if they continue teaching using other approaches, which may increase their expenses. It is worth noting that whereas hospitals are funded to provide PPE, outpatient preceptors' offices are not. Future requirements of PPE for learners in the outpatient setting must be accounted for in medical education funding. Medical education-related professional activities are not particularly well remunerated despite the effort they require from staff physicians. Educators have thus become disincentivized and learners will suffer.

Current regulations for medical licensing require that a terminal assessment be completed. Changing the format of examinations for postgraduate medical learners is difficult. As the Medical Council of Canada discovered in recent examinations delivered online, virtual proctoring as well as connectivity issues present challenges. ${ }^{15}$ Although formal assessment does drive learning, as competency-based assessment progresses and becomes more robust, some hope that examinations will no longer be required in their current form.

The teaching and learning of medicine has historically been slow to change, but rapid changes seen during the COVID-19 pandemic show that the profession is capable of being nimble. The current upheaval represents an opportunity for experimentation in how postgraduate medical education is delivered. As Carl R. Rogers said, "The only person who is educated is the one who has learned how to learn ... and change." It is time to embrace competency-based training and expand the use of technology in postgraduate medical education. 


\section{References}

1. Impact on Royal College exams. Ottawa: Royal College of Physicians and Surgeons of Canada; 2020. Available: www.royalcollege.ca/rcsite/documents/ about/update-coronavirus-e (accessed 2020 July 27).

2. Impact of COVID-19 on certification and examinations. Mississauga (ON): The College of Family Physicians of Canada; 2020. Available: www.cfpc.ca/en/education -professional-development/examinations-and-certification/certification-examination -in-family-medicine/impact-of-covid-19-on-certification-and-examinati (accessed 2020 July 27).

3. Mian A, Khan S. Medical education during pandemics: a UK perspective. BMC Med 2020;18:100.

4. Cox DJ, Plavnick JV, Brodhead MT. A proposed process for risk mitigation during the COVID-19. pandemic. Behav Anal Pract 2020;13:1-7.

5. Schwartz AM, Wilson JM, Boden SD, et al. Managing resident workforce and education during the COVID-19 pandemic. JB JS Open Access 2020;5:e0045. doi: 10.2106/JBJS.OA.20.00045).

6. Oandasan I. Advancing Canada's family medicine curriculum: Triple C. Can Fam Physician 2011;57:739-40, e237-8.

7. Frank JR, Snell L, Sherbino J, editors. CanMEDS 2015: physician competency framework. Ottawa: Royal College of Physicians and Surgeons of Canada; 2015.

8. Competence by Design Launch Schedule. Ottawa: Royal College of Physicians and Surgeons of Canada; 2020. Available: www.royalcollege.ca/rcsite/cbd/ cbd-implementation-e (accessed 2020 June 15).

9. Tekian A, Hodges BD, Roberts TE, et al. Assessing competencies using milestones along the way. Med Teach 2015;37:399-402.

10. Ponce BA, Menendez ME, Oladeji LO, et al. Emerging technology in surgical education: combining real-time augmented reality and wearable computing devices. Orthopedics 2014;37:751-7.

11. Hollander JE, Carr BG. Virtually perfect? Telemedicine for COVID-19. N Engl J Med 2020;382:1679-81.

12. O'Doherty D, Dromey M, Lougheed J, et al. Barriers and solutions to online learning in medical education - an integrative review. BMC Med Educ 2018;18:130.
13. Stambough JB, Curtin BM, Gililland JM, et al. The past, present, and future of orthopaedic education: lessons learned from the COVID-19 pandemic. J Arthroplasty 2020;35:S60-4.

14. Viglione G. How scientific conferences will survive the coronavirus shock [news feature]. Nature 2020 June 2. Available: www.nature.com/articles/d41586-020 -01521-3 (accessed 2020 June 10).

15. Kupfer M. Med school final exam plagued with technical issues after moving online due to COVID-19. CBC News 2020 June 22. Available: www.cbc.ca/news/ canada/ottawa/medical-mcc-exam-technical-issues-1.5619168 (accessed 2020 June 22).

Competing interests: J. Mark Walton is the Chair of the Committee of Specialty Education and is a member of the Council and Executive Committee at the Royal College of Physicians and Surgeons of Canada. No other competing interests were declared.

This article was solicited and has been peer reviewed.

Affiliations: Departments of Surgery (McCarthy, Walton) and Medicine (Carayannopoulos), Faculty of Health Sciences, McMaster University, Hamilton, Ont.; Department of Orthopedics (McCarthy) Brigham and Women's Hospital, Boston, Mass.; Department of Pediatric Surgery (Walton) McMaster Children's Hospital, Hamilton, Ont.

Contributors: All of the authors contributed to the conception and design of the work and drafted the manuscript, and revised it critically for important intellectual content. All of the authors gave final approval of the version to be published and agreed to be accountable for all aspects of the work.

Acknowledgements: The authors thank Dr. Laura Walton and Dr. Helene Boutin for their assistance with editing the manuscript.

Correspondence to: Mark Walton, waltonj@mcmaster.ca 